\title{
Reiseführer auf den Spuren eines Entdeckers
}

Ein Reisebegleiter der etwas anderen Art: „Wilhelm Conrad Röntgen - den X-Strahlen auf der Spur" begleitet seine Leserinnen und Leser zu Wirkungsstätten, Gedenkorten, Forschungsinstituten und Museen und erlaubt so eine Begegnung mit dem Entdecker der Röntgenstrahlen. Hinzu kommen zahlreiche bisher unveröffentlichte Reisefotos aus dem privaten Fotoarchiv von Wilhelm Conrad Röntgen.

\section{Das Unsichtbare wird sichtbar!}

Wilhelm Conrad Röntgens Entdeckung der X-Strahlen am 8. November 1895 an der Universität Würzburg ermöglichte das bisher Verborgene zu durchdringen und sichtbar zu machen. Der Einfluss der später nach ihrem Entdecker benannten Röntgenstrahlen blieb nicht nur auf die Medizin beschränkt. Röntgenstrahlen schrieben und schreiben damals wie auch heute noch Wissenschafts- und Alltagsgeschichte.

Ihr Nutzen für die Medizin ist unumstritten. Ihre kurzen Wellenlängen ermöglichen den Blick bis in Nanowelten. Röntgenlicht aus dem Weltall gibt Auskunft über explodierende Sterne und Schwarze Löcher und moderne Röntgentechnik eröffnet Fenster in die Archäologie. Röntgenstrahlen haben auch heute nichts von ihrer Faszination und Bedeutung verloren.

Ihr Entdecker führte ein bewegtes und interessantes Leben, das inn beruflich und privat in besondere Städte und Landschaften führte. Seine Leidenschaft gehörte der Natur und ihren Phänomenen.

Der kleine Reiseführer lädt ein, auf den Lebens- und Wirkungswegen von Wilhelm Conrad Röntgen zu wandeln, außergewöhnliche Museen und Sammlungen zu entdecken sowie Institutionen modernster Röntgenforschung kennenzulernen.

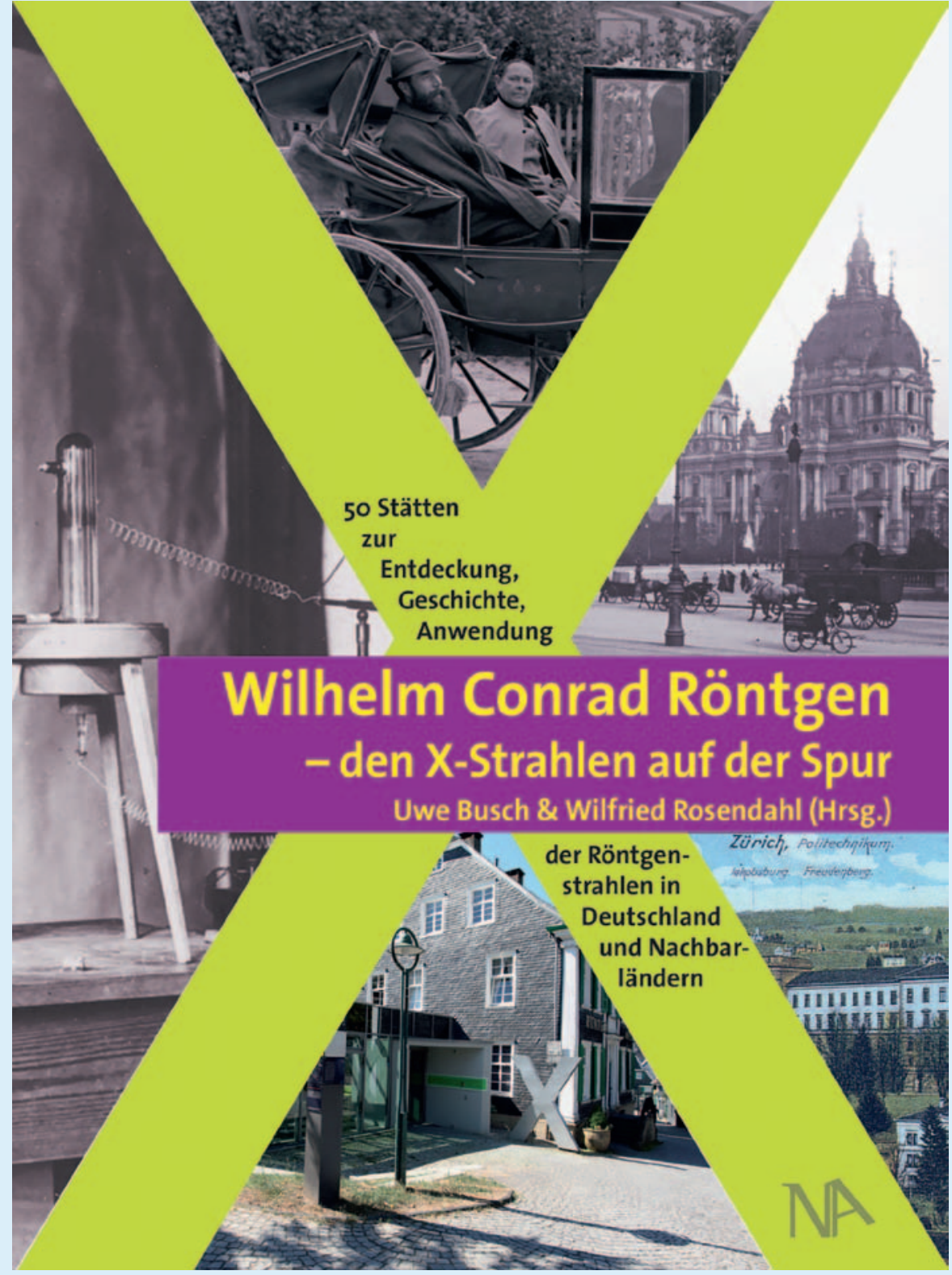

Uwe Busch \& Wilfried Rosendahl (Hrsg) Wilhelm Conrad Röntgen und den X-Strahlen auf der Spur

50 Stätten zur Entdeckung, Geschichte, Anwendung der Röntgenstrahlen in Deutschland und Nachbarländern 120 Seiten

ca. 120 Abbildungen

$15,2 \times 21 \mathrm{~cm}$, Broschur

$€ 18,00$ (D)/ €18,50 (A)

ISBN: 978-3-96176-137-1

WGS: 1943

Oktober 2020
Uwe Busch

Dr., ist Direktor am Deutschen RöntgenMuseum in Remscheid-Lennep.

\section{Wilfried Rosendah}

Prof. Dr., ist Direktor an den Reiss-EngelhornMuseen und Direktor des dortigen CurtEngelhorn-Zentrums für Kunst- und Kulturgeschichte sowie Wissenschaftlicher Vorstand am Curt-Engelhorn-Zentrum Archäometrie und Honorarprofessor am Historischen Institut der Universität Mannheim. 